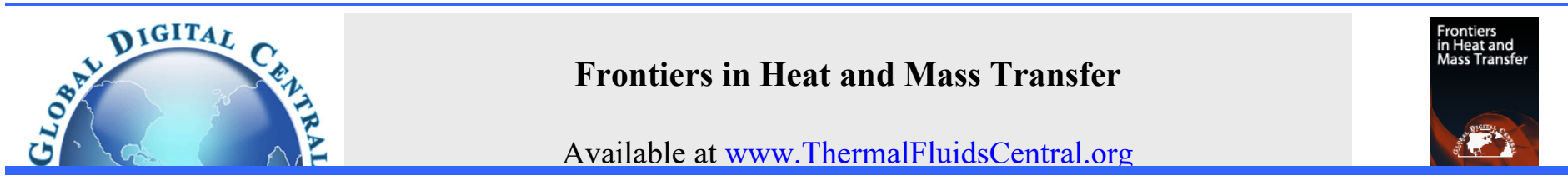

\title{
ENTROPY GENERATION ANALYSIS OF A NATURAL CONVECTION INSIDE A SINUSOIDAL ENCLOSURE WITH DIFFERENT SHAPES OF CYLINDERS
}

\author{
Hussein M. Jassim, Farooq H. Ali ${ }^{*}$, Qusay R. Al-Amir, Hameed K. Hamzah, Salwan Obaid Waheed Khafaji \\ ${ }^{1}$ Mechanical Engineering Department, College of Engineering, University of Babylon, Hilla, Babylon, 51, Iraq
}

\begin{abstract}
This study is focused on the entropy generation of laminar natural convection inside a sinusoidal enclosure filled with air (Pr=0.71). The numerical investigation is performed for three shapes of inner cylinders (circle, square, and equilateral triangle) with the same area and different values of the Rayleigh number $\left(10^{3}-10^{6}\right)$. Galerkin Finite Element Approach is utilized to solve the governing equations. The results showed that the entropy generations due to heat transfer, fluid friction and total entropy generation increase with increasing values of Rayleigh number, while the local Bejan number decreases.
\end{abstract}

Keywords: Natural convection, Entropy generation, Different shapes inner cylinders, Corrugation outer cylinder.

\section{INTRODUCTION}

Today, most thermal systems are submitted to energy loss due to thermal gradients and friction effects, which induces the entropy generation in the system. Therefore, energy saving becomes one of the primary objectives in designing a thermal system for many applications such as thermal storage, environmental comfort, grain drying, electronic cooling, and others. The entropy generation is very important to evaluate the performance of the thermal systems. Many studies have been published concerning the entropy generation inside enclosures using different shapes, methods, fluid types, boundary conditions. Oliveski et al. (2009) presents natural convection due to the temperature difference between the vertical walls of the rectangular enclosure. Their results showed that the amount of dislocated fluid was associated with the heat transfer rate and affected directly the entropy generated. The entropy generation is caused, mainly, by the heat transfer process for Bejan number greater than 0.5 and by the shearing forces predominated for Bejan number less than 0.5. In the same manner, Gediz et al.(2008) studied natural convection mode in a nullity rectangular cavity with different aspect ratios. It was found that for a cavity with a high value of the Rayleigh number (i.e., $\mathrm{Ra}=10^{5}$ ), the total entropy generation due to fluid friction and total entropy generation increased with increasing aspect ratios. Nithyadevi et al. (2017) studied four cases using a discrete heater to maintain isothermal conditions. They investigated the effect of Prandtl number with internal heat generation parameter on natural convection in a rectangular enclosure. The results were formed as streamlines, isotherms, velocity profiles with an average Nusselt number. The researches Basak et al. (2011) Morsli and Sabeur-Bendehina (2014), Nejad (2017), Shi et al. (2017), Yehya and Naji (2015) and Erbay et al. (2003), studied entropy generation in square enclosures with different cases. Basak et al. (2011) presented a square cavity subjected to linearly cool from the sides and hot isothermal bottom while the top assumed fully insulated to reach a minimum entropy generation. It was found that the heat transfer irreversibility dominated the entropy generation in the cavity with low Ra value, while the maximum entropy generation due to heat transfer occurred near the hot-cold junctions due to high thermal gradients. Also, the entropy generation due to frictional irreversibility was lower as fluid flow was weak at low Ra. Morsli and SabeurBendehina (2014) compared the mean Nusselt number between hot cavity square walls and hot wavy walls, where the entropy generation increased as undulation number increased according to this result. They indicated that the mean Nusselt number and the total entropy generation both increased as the Rayleigh number increased. Nejad (2017) used two semiconductors in the square electronic package as test samples for symmetrical cooling of side walls and a hot bottom. He showed that the minimum entropy generation rate obtained as the peak heater temperature in minimum value. Two-dimensional square enclosure with various ranges of Bejan number was studied by Shi et al. (2017) where used a magnetic quadruple field to minimize the irreversibility of the system. The simulation results of coupled equations for the flow, energy and entropy generation were presented in terms of streamlines, isotherms, local entropy generation contours, and total entropy generation. Yehya and Naji (2015) employed the thermal lattice Boltzmann method to study convective melting for the square enclosure. The results were controlled in low Prandtl numbers by the heat transfer while its variation dominated by shearing losses for high Prandtl numbers. Erbay et al. (2003) studied entropy generation in square enclosures for completely or partially heated wall, while the other side was cooled and the top and bottom assumed adiabatic. Their results indicated the same active sites magnitude difference in the corner for completely, and this magnitude varied depending on Prandtl and Grashof numbers in partial heated walls. Kumar et al.(2012) simulated the entropy generation inside the rhombic enclosure to find the location of the maximum and minimum local entropy generation. The enclosure was heated non-uniformly from the bottom walls, while the side walls were insulated and the top wall was cooled to a constant temperature. The results revealed that the local entropy generation during natural convection was maximum at the middle of the side walls, while it has become minimum at the center. Mahmud and Islam (2003) applied the second law of thermodynamics to predict the nature of irreversibility in

\footnotetext{
*Corresponding Author. Email: farooq_hassan77@yahoo.com
} 
the inclined wavy wall cavity. Hussein et al.(2016) showed a numerical computation of unsteady laminar three-dimensional natural convection and entropy generation in an inclined cubical trapezoidal air-filled cavity. The vertical right and left side walls of the cavity were maintained at constant cold temperatures and the lower wall was subjected to a constant hot temperature, while the upper one was considered insulated. Kucuk (2010) presented a numerical analysis of entropy generation in concentric curved annular ducts with a constant wall temperature boundary condition. As Dean Number increased, the distribution of volumetric entropy generation resulting from heat transfer irreversibility and the total volumetric entropy generation was formed by the temperature field depending on the curvature under constant wall temperature boundary condition. Also, the maximum entropy generation was found near the proper wall of the heart because of the maximum temperature gradient resulting from the centrifugal force.

However, efforts are made to study the second law analysis in different cavities filled with nanofluids. Sheremet et al.(2016) used the finite volume method to investigate the effects of solid isothermal partition insertion in a nanofluid filled cavity that is cooled via corner isothermal cooler. Al-Zamily and Amin (2015) studied the effects of the presence of nanoparticles on natural convection and entropy generation in a semicircular enclosure with presence heat flux. The enclosure was filled with nanofluids ( $\mathrm{Cu}$-water). The influence of pertinent parameters such as Rayleigh number and solid volume fraction of nanoparticles on the flow, temperature, and entropy generation was presented. Results showed that the heat transfer rate increased with an increase of the both Rayleigh number and the nanoparticles volume fraction as well as the system irreversibility increased with an increase of nanoparticles fraction. Alsabery et al. (2018) studied entropy generation analysis and natural convection in a nanofluid-filled square cavity with a concentric solid insert and different temperature distributions. It was found very strong enhancement in the heat transfer rate with the increasing of Rayleigh number from $10^{4}$ to $10^{5}$. Also, the thermal property and the size of the inner solid square significantly influenced the rate of the hightemperature transport. Furthermore, the higher thermal conductivity of the solid insert led to increasing the heat transfer rate.

Several studies about the second law of thermodynamics are also focused on cavities saturated with a porous medium. Kaluri and Basak (2011) numerically took into consideration the effects of the permeability of the porous medium and the role of distributed heating in enhancing the thermal mixing, temperature uniformity and minimization of entropy generation. They found that at lower Darcy number (Da), the thermal mixing was low and the heat transfer irreversibility dominated the total entropy generation. They also found that the distributed heating methodology with multiple heat sources may be an effective strategy for the optimal thermal processing of materials. Hussain (2016) conducted a numerical study of natural convection inside enclosure filled with an electrically conducting fluid $(\mathrm{Pr}=0.024)$ saturated with a porous medium. The top and bottom horizontal walls were adiabatic and non-diffusive, while the left and right vertical corrugated sidewalls were maintained at a constant hot and cold temperatures and concentrations, respectively. The flow in the enclosure was subjected to an inclined magnetic field. The results showed that the average Nusselt and Sherwood numbers increased with increasing both the Darcy number and buoyancy ratio. Moreover, the results showed that the entropy generations due to the horizontal magnetic field were higher than the corresponding values when its subjected to the vertical magnetic field. Mahmud and Fraser (2004) investigated the problem of entropy generation in a fluid-saturated porous cavity for laminar magneto-hydrodynamic natural convection. Ismael et al.(2016) studied numerically the entropy generation due to conjugate natural convection and conduction heat transfer in a square cavity filled with a nanofluid-saturated porous media. The results showed that together the entropy generation and the average Nusselt number increase with increasing the thermal conductivity ratio. Qusay et al.(2017) indicated numerically the effect of wavy wall locations on natural convection flow in a two dimensional enclosure filled with air containing a concentric heated circular cylinder. They used a Galerkin finite element approach in their simulation. The governing equations with boundary conditions were solved iteratively using the Tri-Diagonal Matrix Algorithm (TDMA). A. Kumar Singh et al.(2014) studied numerically based on the Galerkin finite element method the entropy generation during natural convection within the tilted square cavity inclined with different angles and thermal boundary conditions. They concluded that the finite element approach offered unique advantages over finite difference or finite volume methods when the elemental basis sets were used for the calculation of gradients or derivatives for evaluation of entropy generation due to heat transfer and flow irreversibilities. Ammar Abdulkadhim et al.(2017) study the natural convection and entropy generation inside trapezoidal cavity with the presence of baffles. The cavity filled with $\mathrm{Cu}$-water as a working fluid. Finite Element Method is used to solve the governing equations. The results show that at high Rayleigh number, the entropy generation caused by fluid friction was higher than caused by fluid flow.

In the present study, the scope of this work is to investigate the natural convection in a sinusoidal enclosure having concentric inner cylinder using analysis of entropy generation. The effects of the three geometries of inner cylinders, including circle, square, and equilateral triangle, and different Rayleigh numbers are also investigated. The reason for using such a special shape is to study fluid flow and heat transfer in addition to the entropy generation for the case of natural convection with the presence of the different shape of inner cylinders. M. Sheikholeslami et al. (2012), (2013) is the first researcher descripes the corrugation circular cylinder with a different formula from the equation $1 \& 2$ mentioned in the this paper.

\section{PROBLEM CHARACTERIZATION}

The considered problem is schematically illustrated in Fig. 1. It is consists of a circular corrugation cylinder with a number of corrugations equal to $(N=3)$, which are isothermally cooled, while the inner cylinder is isothermally heated and placed at the middle of the enclosure. The outer corrugation circular cylinder is plotted according to the following equations.

$$
\begin{aligned}
& X=\left[R_{b}+\lambda \sin \left(N * \varphi * \frac{\pi}{180}\right) / N\right] *\left(\cos \left(\varphi * \frac{\pi}{180}\right)\right) \\
& Y=\left[R_{b}+\lambda \sin \left(N * \varphi * \frac{\pi}{180}\right) / N\right] *\left(\sin \left(\varphi * \frac{\pi}{180}\right)\right)
\end{aligned}
$$

Where $R_{b}$ is the base circle, $\lambda$ is the amplitude, $N$ is the number of corrugations and $\varphi$ is the rotation angle. The dimensional parameter $\left(\mathrm{R}=\mathrm{R}_{\mathrm{o}}-\mathrm{R}_{\mathrm{i}}\right)$ is equal to unity which represent the annulus space. The outer and inner cylinders are concentric cylinders which have the same center in the origin.

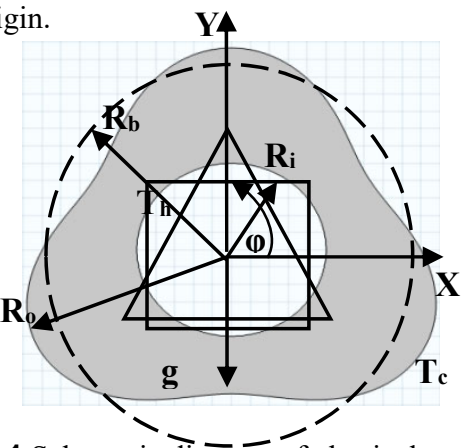

Fig. 1 Schematic diagram of physical model

The inner cylinder is a highly conductive object. The dimensionless surface area for different shapes of cylinders (circle, square, and equilateral triangle) is one. In the present problem, the heat transfer in the enclosure occurs by natural convection and fluid flow is assumed a Newtonian, steady, laminar and incompressible. The problem is using the air as a working fluid with $(\mathrm{Pr}=0.71)$. The air properties are constant except for the density change according to the Boussinesq approximation while the viscous dissipation term in the energy equation is neglected, but is considered for estimation of entropy generation due to heat transfer 
( $\left.\mathrm{S}_{\mathrm{T}, \mathrm{HT}}\right)$, fluid flow $\left(\mathrm{S}_{\mathrm{T}, \mathrm{FF}}\right)$, total entropy generation $\left(\mathrm{S}_{\mathrm{L}}\right)$, and Bejan number $\left(\mathrm{Be}_{\text {mean }}\right)$. The effects of radiation are neglected.

\section{MATHEMATICAL FORMULATION AND SIMULATION}

For the present study conditions, governing equations for steady twodimensional natural convection flow in the corrugation cylinder enclosure using conservation of mass, momentum, and energy can be written in dimensionless formula:

$\frac{\partial U}{\partial X}+\frac{\partial V}{\partial Y}=0$

$U \frac{\partial U}{\partial X}+V \frac{\partial U}{\partial Y}=-\frac{\partial P}{\partial X}+\operatorname{Pr}\left(\frac{\partial^{2} U}{\partial X^{2}}+\frac{\partial^{2} U}{\partial Y^{2}}\right)$

$U \frac{\partial V}{\partial X}+V \frac{\partial V}{\partial Y}=-\frac{\partial P}{\partial Y}+\operatorname{Pr}\left(\frac{\partial^{2} V}{\partial X^{2}}+\frac{\partial^{2} V}{\partial Y^{2}}\right)+\operatorname{Ra} \operatorname{Pr} \theta$

$U \frac{\partial \theta}{\partial X}+V \frac{\partial \theta}{\partial Y}=\left(\frac{\partial^{2} \theta}{\partial X^{2}}+\frac{\partial^{2} \theta}{\partial Y^{2}}\right)$ below.

The dimensionless variables in equations 4-6 are described as

$$
\begin{aligned}
X=\frac{x}{R} ; Y=\frac{y}{R} ; U= & \frac{u}{u_{b}} ; V=\frac{v}{u_{b}} ; P=\frac{p}{\rho u_{b}{ }^{2}} ; \theta=\frac{T-T_{c}}{\Delta T} ; \Psi=\frac{\Psi}{u_{b} R} ; R \\
& =\frac{g \beta(\Delta T) R^{3}}{v^{2}} ; \operatorname{Pr}=\frac{v}{\alpha}
\end{aligned}
$$

The boundary conditions for the present study are expressed as follows:

I- $\quad$ Inner cylinders $\mathrm{U}=\mathrm{V}=0, \mathrm{~T}=\mathrm{T}_{\mathrm{h}}=1$.

II- Outer corrugation circular cylinder $\mathrm{U}=\mathrm{V}=0, \mathrm{~T}=\mathrm{T}_{\mathrm{c}}=0$

The local Nusselt number around the hot inner cylinders is expressed by

$N u_{L o c}=-\frac{\partial \theta}{\partial n}$

Where $n$ is the normalized direction to the hot inner cylinder surface, while the average Nusselt number around it is given by:

$N u_{m}=\frac{1}{l_{c}} \int_{0}^{l_{c}} N u_{\text {Loc }}(\varphi) d \varphi$

As the non-dimensional variables expressed in Eq.(7) and from thermodynamic equilibrium theory for linear transport A. Kumar Singh et al.(2014).

The dimensionless equations for the entropy generation for both heat transfer and fluid friction for two-dimension of the present study in the xy-coordinates are written in the following form:

$S_{T, H T}=\left(\frac{\partial \theta}{\partial X}\right)^{2}+\left(\frac{\partial \theta}{\partial Y}\right)^{2}$

$S_{T, F F}=\phi\left\{2\left[\left(\frac{\partial U}{\partial X}\right)^{2}+\left(\frac{\partial V}{\partial Y}\right)^{2}\right]+\left(\frac{\partial U}{\partial Y}+\frac{\partial V}{\partial X}\right)^{2}\right\}$

The summation of entropy generation is:

$S_{T T}=S_{T, H T}+S_{T, F F}=\left(\frac{\partial \theta}{\partial X}\right)^{2}+\left(\frac{\partial \theta}{\partial Y}\right)^{2}+\phi\left\{2\left[\left(\frac{\partial U}{\partial X}\right)^{2}+\left(\frac{\partial V}{\partial Y}\right)^{2}\right]+\right.$

$\left.\left(\frac{\partial U}{\partial Y}+\frac{\partial V}{\partial X}\right)^{2}\right\}$

Where, $\varnothing$ is the ratio of irreversibility distribution, which defined

as:

$\emptyset=\frac{S_{T . F F}}{S_{T, H T}}=\frac{\mu T_{o}}{k}\left(\frac{\alpha}{R \Delta T}\right)^{2}$

The overall entropy generation is achieved by integration of the entropy generation across the system volume.

$S_{o, H T}=\int_{v} S_{T, H T} d v$

$S_{o, F F}=\int_{v} S_{T, F F} d v$
The Bejan number number illustrate the strength of irreversibility caused by heat transfer entropy generation.

$$
B e_{T}=\frac{S_{T, H T}}{S_{T}}
$$

The mean Bejan number is achieved to calculate the irreversibility of heat transfer entire the annulus enclosure.

$B e_{\text {mean }}=\frac{\int_{A} B e(x, y) d A}{\int_{A} d A}$

\section{COMPUTATIONAL METHODOLOGY}

The governing equations (3-6) with the boundary conditions are determined numerically by the using Galerkin Finite Element Approach. The Incompressible Navier-Stokes application mode (NS), the Convection-Conduction application mode (CC), and the Diffusion application mode (DI) are used for equations $(3,4,5$, and 6) respectively. $\mathrm{P}_{2}-\mathrm{P}_{1}$ Lagrange elements and the Galerkin least-square method are used to convince stability. A parallel direct solver (PARDISO) and the damped Newton method are applied to resolve the discretized equations. Here the convergence criterion is set to $10^{-6}$. For more information, see Zienkiewicz and Taylor (2000).

In this work, triangular finite elements are exhausting to generate the mesh interior the annulus enclosure. The triangular mesh distribution is exposed in Figure (2a). To obtain a grid sensitivity independent. The mean Nusselt number is chosen to predict the mesh independence since the mean Nusselt number represent global parameter and not change when the solution is stable. Figure (2b) represents the convergence of the mean Nusselt number of the hot inner square cylinder with number of elements. The figure (2b) shows that the mean Nusselt number has insignificant change after 20000 elements with finer grid. The sensitivity is established to be exceptional, which confirms the present computational study.
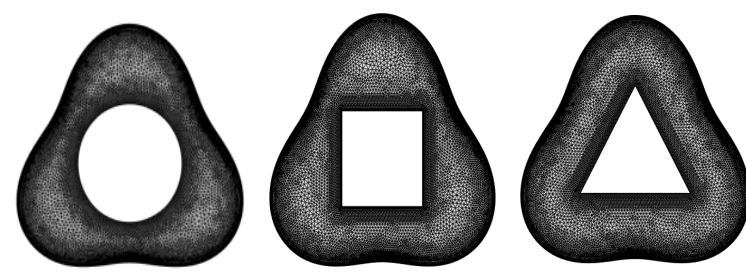

Fig. 2a Mesh of the present study, $\mathrm{N}=3$ for different inner cylinder

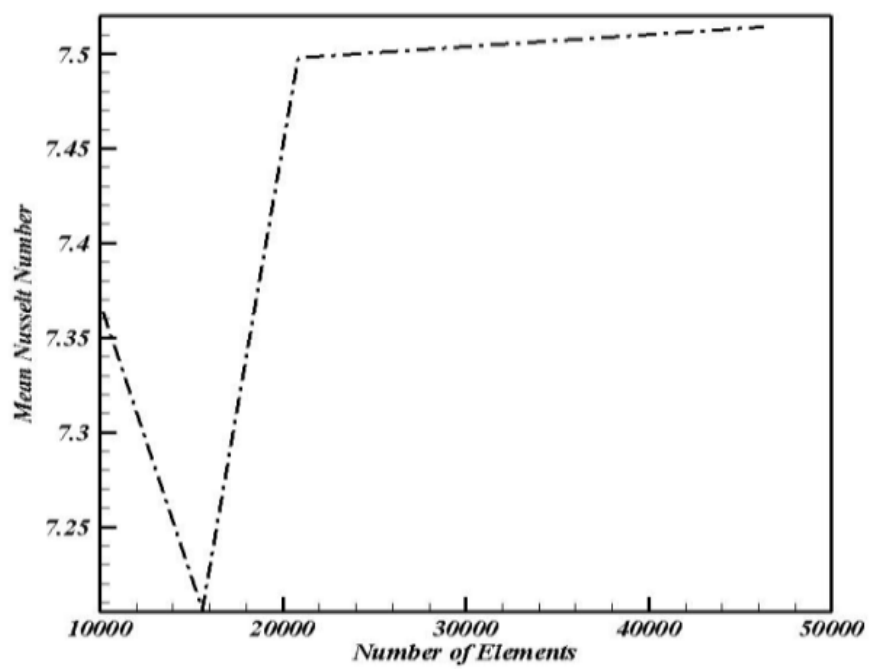

Fig. 2b Mesh generation independency 
A comparitive finer mesh with 40000 elements has been chosen for the whole set of the current study. Fig. 3 displays a comparison check of the numerical program to get free of errors.

The present computational numerical study is verified against the study published by S. M. Shavik et al.(2013) which deals with entropy generation inside square inclined cavity with differentially heated vertical walls. The comparison included the results of the stream function, isothermal lines, entropy generation due to friction and heat transfer, total entropy and local Bejan number. Very well agreement is obtained between the results of the present work and S. M. Shavik et al.(2013) These comparisons formed an excellent assurance in the current computation study to deal with the physical problem.

The comparison of total entropy and mean Bejan number between the present study and results of S. M. Shavik et al.(2013) and G. G. Ilis et al.(2008) are reported in Table 1.

Table 1: Comparison of total entropy generation and mean Bejan number for $\operatorname{Pr}=0.71, \phi=10^{-4}$

\begin{tabular}{|l|c|c|c|c|c|c|}
\hline \multirow{2}{*}{$\mathrm{Ra}$} & \multicolumn{2}{|l|}{ Present Study } & \multicolumn{2}{c|}{$\begin{array}{c}\text { S. M. Shavik et } \\
\text { al.(2013) }\end{array}$} & \multicolumn{2}{c|}{$\begin{array}{c}\text { G.G. Ilis } \text { et } \\
\text { al.(2008) }\end{array}$} \\
\cline { 2 - 7 } & $\mathrm{S}_{\mathrm{TT}}$ & $\mathrm{Be}_{\text {mean }}$ & $\mathrm{S}_{\mathrm{TT}}$ & $\mathrm{Be}_{\text {mean }}$ & $\mathrm{S}_{\mathrm{TT}}$ & $\mathrm{Be}_{\text {mean }}$ \\
\hline $10^{3}$ & 1.152 & 0.965 & 1.15 & 0.97 & 1.2 & 0.96 \\
\hline $10^{4}$ & 23.27 & 0.199 & 23.27 & 23.27 & 23.5 & 0.20 \\
\hline
\end{tabular}

\section{RESULTS AND DISCUSSION}

The posed problem in this work deals with entropy generation analysis for laminar natural convection inside the sinusoidal enclosure filled with air and containing a concentric inner cylinder under steady-state conditions. Effects of different shapes of cylinders and Rayleigh numbers on the flow and thermal fields are examined and discussed here. All the contours under the study are symmetrical about the vertical centerline of the enclosure because of the symmetrical boundary conditions about the Y-axis

Fig. 4 shows the streamlines and isotherms contours for different values of Rayleigh number. When Ra is increased to $10^{3}$, the fluid motion is weak inside the enclosure due to its lower effect of the buoyancy flow. The streamlines contours in this range of the Rayleigh number tend to appear with two rotating eddies on both sides of the enclosure with the exception equilateral triangle shape of inner cylinder where there is one longitudinal eddy on both sides of the enclosure. On the other hand, thermal stratification appears in the enclosure due to the weak motion of the fluid. Consequently, heat is transferred by heat conduction (diffusion). In other words, buoyancy forces are not strong enough to activate significant convection. As the Ra increases from $10^{3}$ to $10^{4}$, the effect of conduction heat transfer decreases due to the increase of flow circulation more than the previous state. Therefore, the buoyancy force increases over viscous force. The values of the maximum stream function are also increased more with increasing of the Rayleigh number ( $\Psi_{\max }=4.38$ to 18.558 for circle shape, $\Psi_{\max }=5.08$ to18.9 for square shape and $\Psi_{\max }=4.409$ to 23.01 for triangle shape). The slope of isotherms contours starts to curve towards the right and left sides of enclosure walls due to the convection heat transfer. The convection currents become more considerable as the Rayleigh number increases to $10^{5}$. For this reason, the difference in the values of the maximum stream function becomes more ( $\Psi_{\max }=60.22$ for circle shape, $\Psi_{\max }=54.454$ for square shape and $\Psi_{\max }=48.88$ for triangle shape. The nuclei of eddies move upward due to the increase of buoyancy. With further increase in the Rayleigh number $\left(\mathrm{Ra}=10^{6}\right)$, the flow strengthens and the maximum stream function values increase more $\left(\Psi_{\max }=+99.6\right.$ for circle shape, $\Psi_{\max }=98.41$ for square shape and $\Psi_{\max }=97.913$ for triangle shape). This is because the flow is reinforced at the top surface of the inner cylinder as illustrated in all shapes. The buoyancy force dominates over the entire domain of flow pace. The isothermal curves are highly inclined toward the sinusoidal walls of enclosure with increasing $\mathrm{Ra}$, which is due to increase energy transmission. (a)

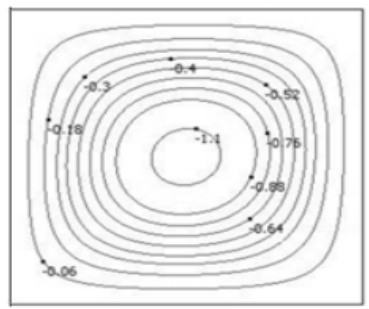

Stream lines

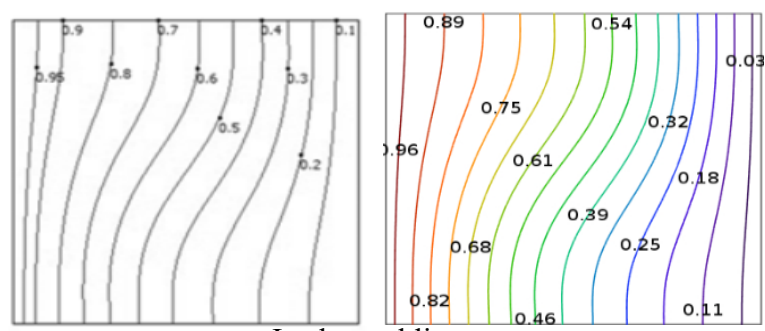

Isothermal lines

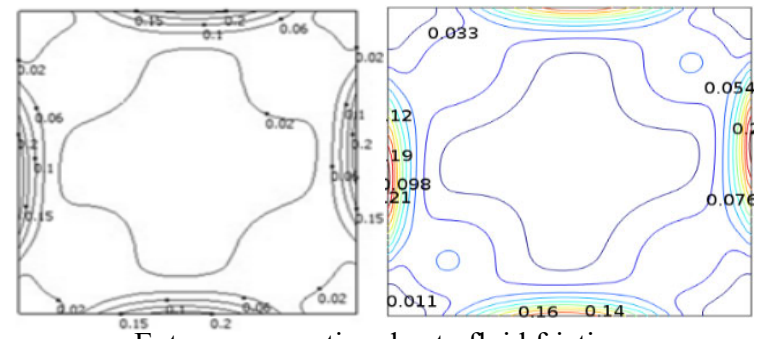

Entropy generation due to fluid friction
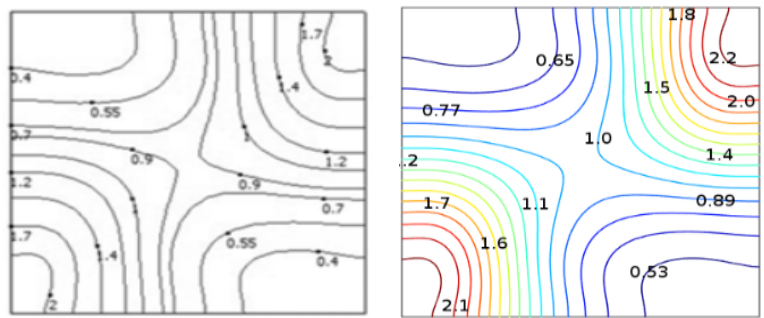

Entropy generation due to heat transfer
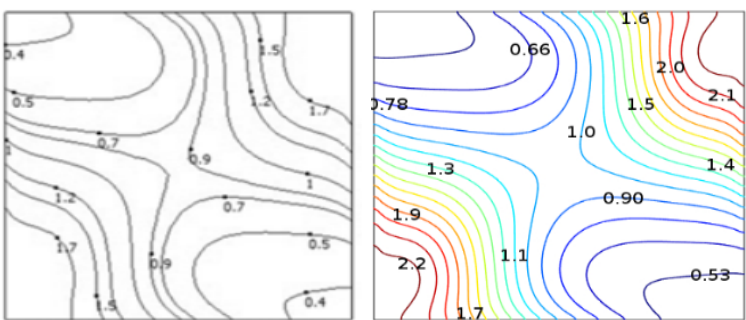

Total entropy generation

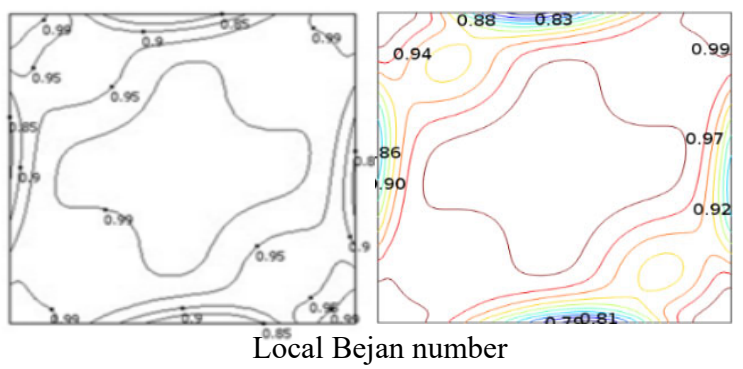

Fig. 3 Stream lines, Isothermal lines, Entropy generation due to fluid friction, Entropy generation due to heat transfer, Total entropy generation, Local Bejan number at $\mathrm{Ra}=10^{3}$, (a) Shavik et al.(2013) (b) Present study 

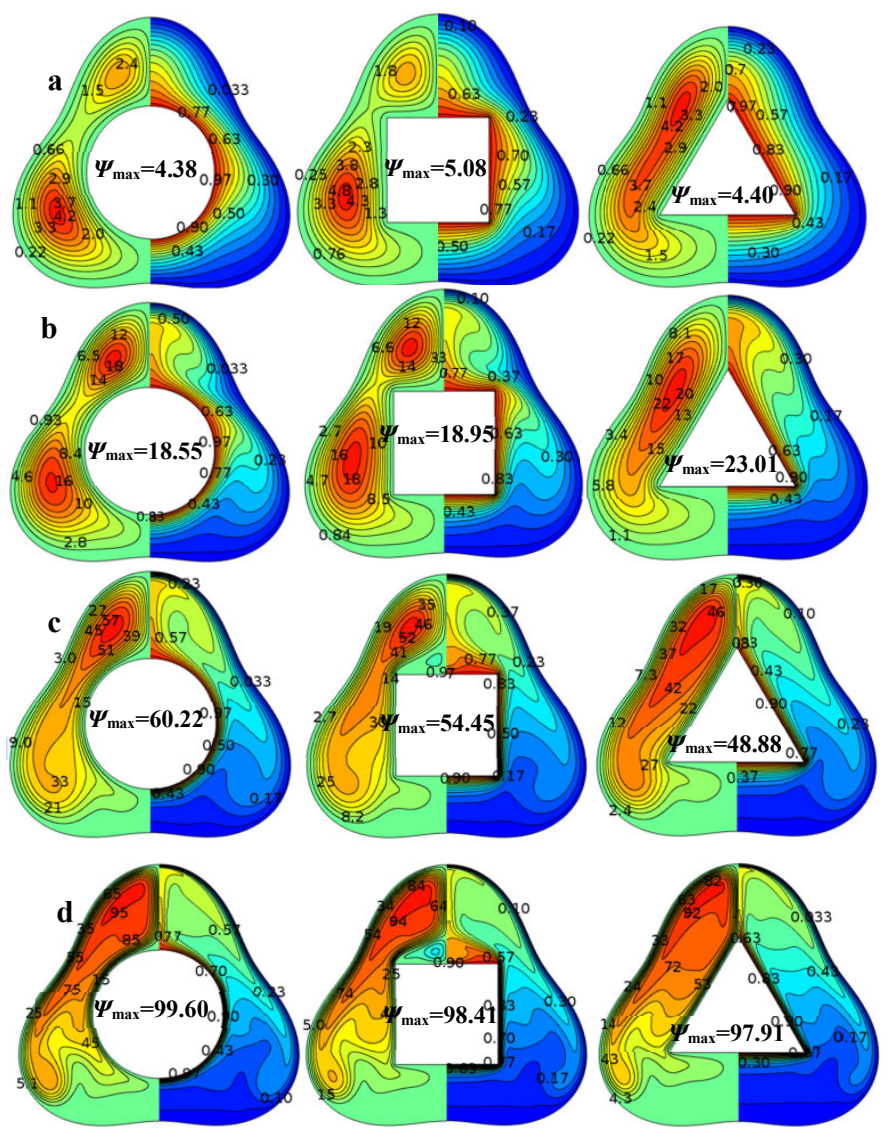

Fig. 4 Streamlines (left half) and Isotherms (right half) for different shapes of inner cylinders (a) $\mathrm{Ra}=10^{3}$, (b) $\mathrm{Ra}=10^{4}$, (c) $\mathrm{Ra}=10^{5}$, (d) $\mathrm{Ra}=10^{6}$.

Fig. 5 demonstrates the irreversibilities due to heat transfer for different values of Rayleigh number. The entropy generation due to heat transfer is dependent on the temperature gradient and accordingly, there is a connection between the entropy generation to heat transfer and the isotherm contour. The entropy generation due to heat transfer diffuses by conduction mode in the gap between the enclosure walls and the inner cylinder when $\mathrm{Ra}$ is increased to $10^{3}$. The conduction effect reduces as $\mathrm{Ra}$ increases to $10^{4}$; therefore, the maximum entropy generation increases in the bottom region for circle shape as well as for both the edges of square and triangle shapes of the hot inner cylinder. With further increases of the Rayleigh number $\left(10^{5}\right)$, entropy generation due to heat transfer increases more because of the steeper temperature gradient at the walls. Therefore, the maximum entropy generation concentrated in the upper region of a sinusoidal wall for all shapes of the inner cylinder. The curve behavior continues same as those when $\mathrm{Ra}$ is increased to $10^{6}$ for all cases. From above, the entropy generation is concentrated along the heated and cooled walls where the temperature gradient is maximized.

Fig. 6 depicts the effect of Ra on entropy generation due to fluid flow inside the enclosure. It is observed that the dominant source of irreversibility is due to fluid flow. There is a significant reduction in the entropy generation as the Rayleigh number changes its value from $10^{5}$ to $10^{6}$. This occurrence is due to a smaller thermal gradient near the side wall, because of higher thermal mixing near the core of the sinusoidal wall of the enclosure

Fig. 7 shows the influence of the Rayleigh number on the total entropy generation contours for different shapes of inner cylinders. As it can be seen, the total entropy generation in the enclosure increases with an increase of Rayleigh number, which is the result of the simultaneous rise in the value of entropy generated by fluid friction and heat transfer by increasing Rayleigh number.
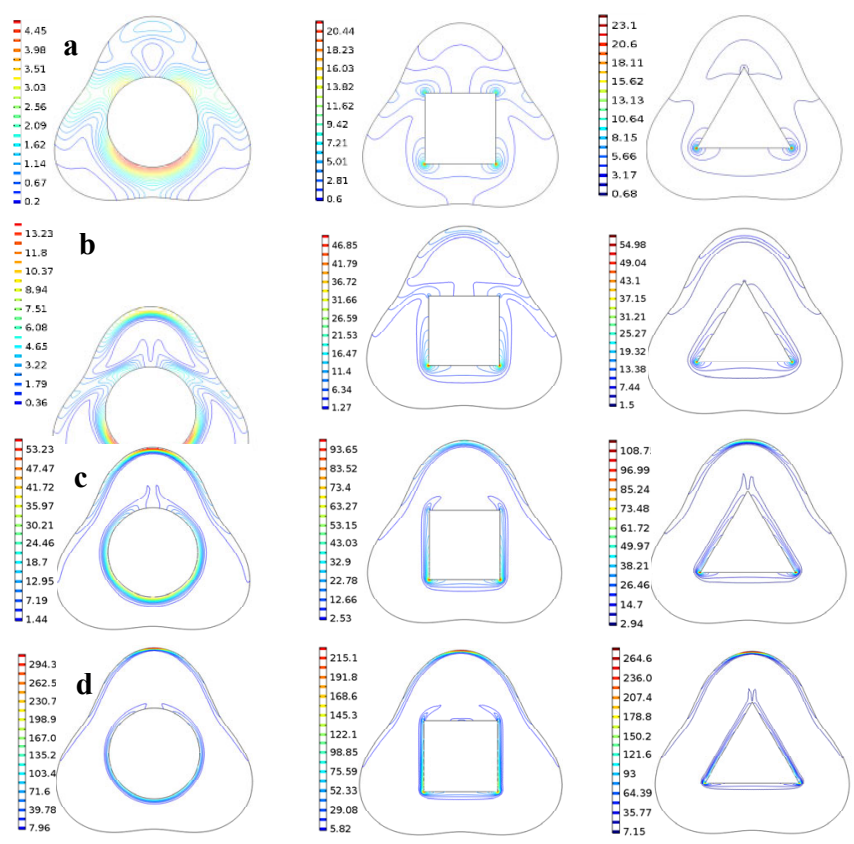

Fig. 5 Local entropy generation due to heat transfer for different shapes for inner cylinders (a) $\mathrm{Ra}=10^{3}$, (b) $\mathrm{Ra}=10^{4}$, (c) $\mathrm{Ra}=10^{5}$, (d) $\mathrm{Ra}=10^{6}$.

In fig. 7, the total entropy generation has a similar contour with the entropy generation due to the fluid flow especially with increasing Rayleigh numbers. This behavior exposes the domination of the fluid flow irreversibility at high Rayleigh number.

Fig. 8 reveals the distributions of Bejan number versus the different values of Rayleigh number. The dimensionless number called Bejan number is represented by the ratio the heat transfer irreversibility to the total irreversibility.
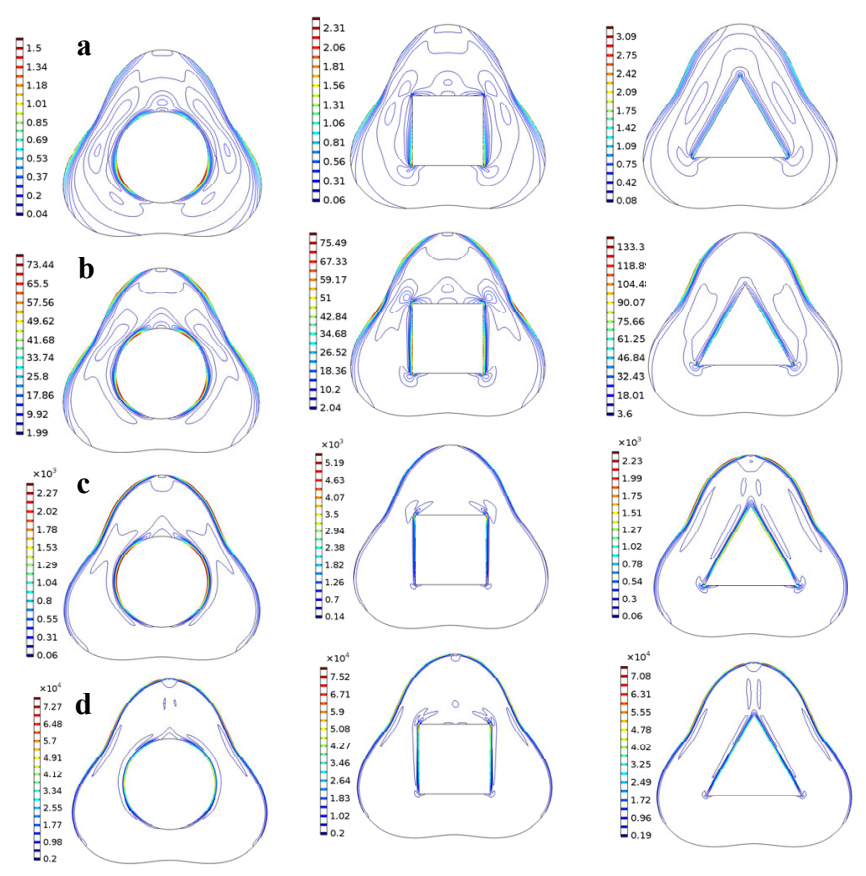

Fig. 6 Local entropy generation due to fluid flow for different shapes of inner cylinders, (a) $\mathrm{Ra}=10^{3}$, (b) $\mathrm{Ra}=10^{4}$, (c) $\mathrm{Ra}=10^{5}$, (d) $\mathrm{Ra}=10^{6}$. 

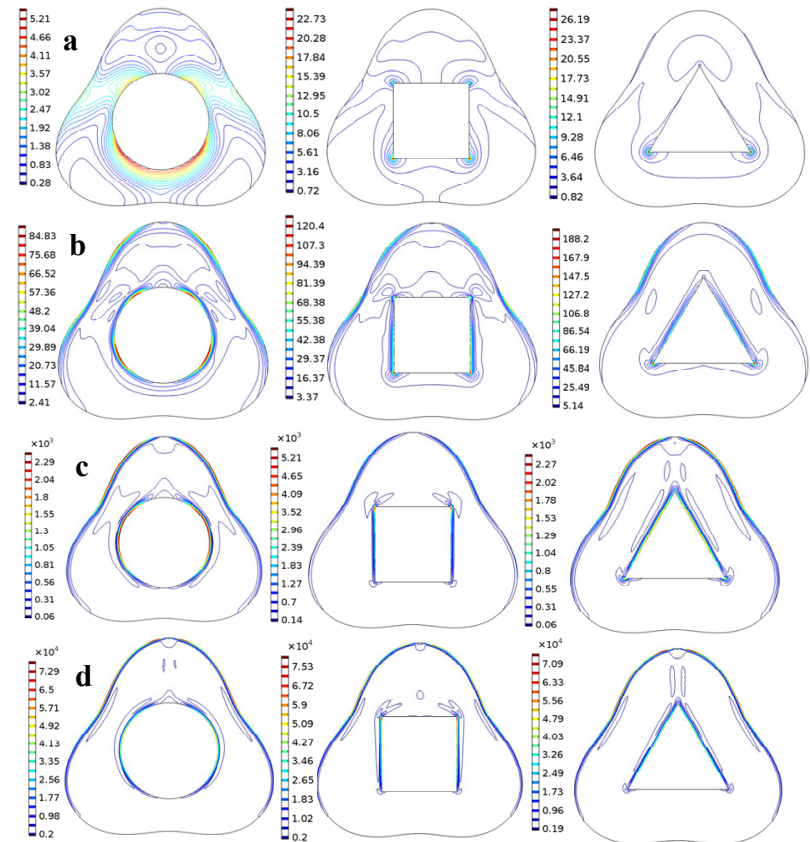

Fig. 7 Total entropy generation for different shapes of inner cylinders, (a) $\mathrm{Ra}=10^{3}$, (b) $\mathrm{Ra}=10^{4}$, (c) $\mathrm{Ra}=10^{5}$, (d) $\mathrm{Ra}=10^{6}$.

As previous discussion, when $\mathrm{Ra}=10^{3}$ the heat transfer is dominated by conduction mode due to its lowering effect of the buoyancy. Consequently, the heat transfer irreversibility controlled by the entire area inside the gap between the sinusoidal enclosure walls and the inner cylinder due to $\mathrm{Be}>1 / 2$. While, the fluid flow irreversibility dominates at the below side in contact with sinusoidal walls due to $\mathrm{Be}<1 / 2$. As $\mathrm{Ra}$ increases to $10^{4}$, buoyancy effect in whole domain. The heat transfer irreversibility spreads as eddies near both the surfaces of the inner cylinder and sinusoidal walls of enclosures for all shapes. On other hand, the fluid flow irreversibility increases around the surface of cylinder except the below region of cylinder for all cases. Other increases of $\mathrm{Ra}$ $\left(10^{5}\right)$, the flow circulation increases than the other cases. Therefore, fluid flow irreversibility dominates along the surface of the inner cylinder and sinusoidal walls of the enclosure except the lower positions of a cylinder and upper region of the lower sinusoidal wall. This is due to the effective fluid motion coming from the higher temperatures near the hot cylinders toward the enclosure walls. Further increases of $\mathrm{Ra}\left(\mathrm{Ra}=10^{6}\right)$, the maximum stream function values increase more and the flow strengthens. Thermal heat transfer is predominant near the lower positions of cylinders and upper region of the lower sinusoidal wall, while the effect of viscosity flow on the entropy generation spreads inside the gap between the walls of the enclosure and the inner cylinder. The Bejan number for the circle shape of inner cylinder is lower than for other shapes for all values of Ra.

The local Nusselt number distributions around a hot inner cylinder for different shapes of cylinders and Rayleigh numbers are presented in Fig. 9. The local $\mathrm{Nu}$ depends on the temperature gradient at the wall which in turn depends on the thickness of the thermal boundary layer. For low $\mathrm{Ra}\left(\mathrm{Ra}=10^{3}\right)$, the local $\mathrm{Nu}$ diagram tends to appear two peaks around the inner cylinder of inner cylinders specifically at $\theta=60^{\circ}$ and $120^{\circ}$ for circle shape, $\theta=270^{\circ}$ and $360^{\circ}$ for a square shape, and $\theta=240^{\circ}$ and $360^{\circ}$ for triangle shape. The same result can be noticed at $\mathrm{Ra}=10^{4}$. As $\mathrm{Ra}$ increases between $10^{5}$ to $10^{6}$, the maximum value of the local Nusselt number appears noticeably near the bottom region of the circular cylinder $\left(\theta=90^{\circ}\right)$, while the maximum values of the local Nusselt number for triangle and square shapes of inner cylinder tend to appear at $\theta=240$ and 270, respectively. These peaks are resulted from highest temperature gradients at the heated surface of the inner cylinder because of thin thermal boundary layer thickness. Consequently, the local heat transfer rate substantially improves with increasing the Rayleigh numbers.

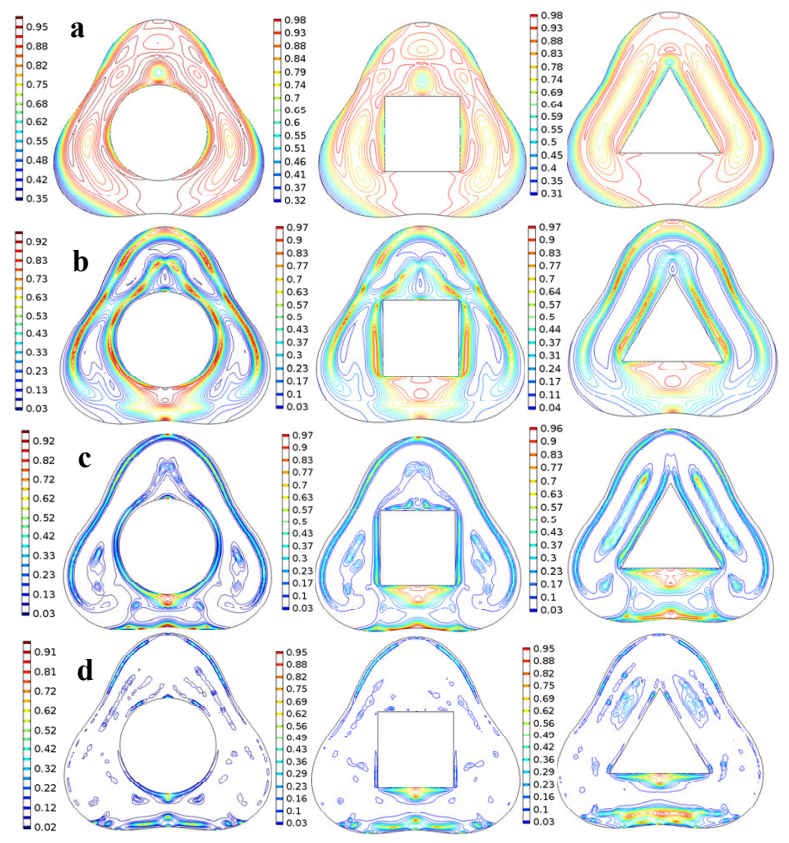

Fig.8. Bejan number for different shapes of inner cylinders, (a) $\mathrm{Ra}=10^{3}$, (b) $\mathrm{Ra}=10^{4}$, (c) $\mathrm{Ra}=10^{5}$, (d) $\mathrm{Ra}=10^{6}$.
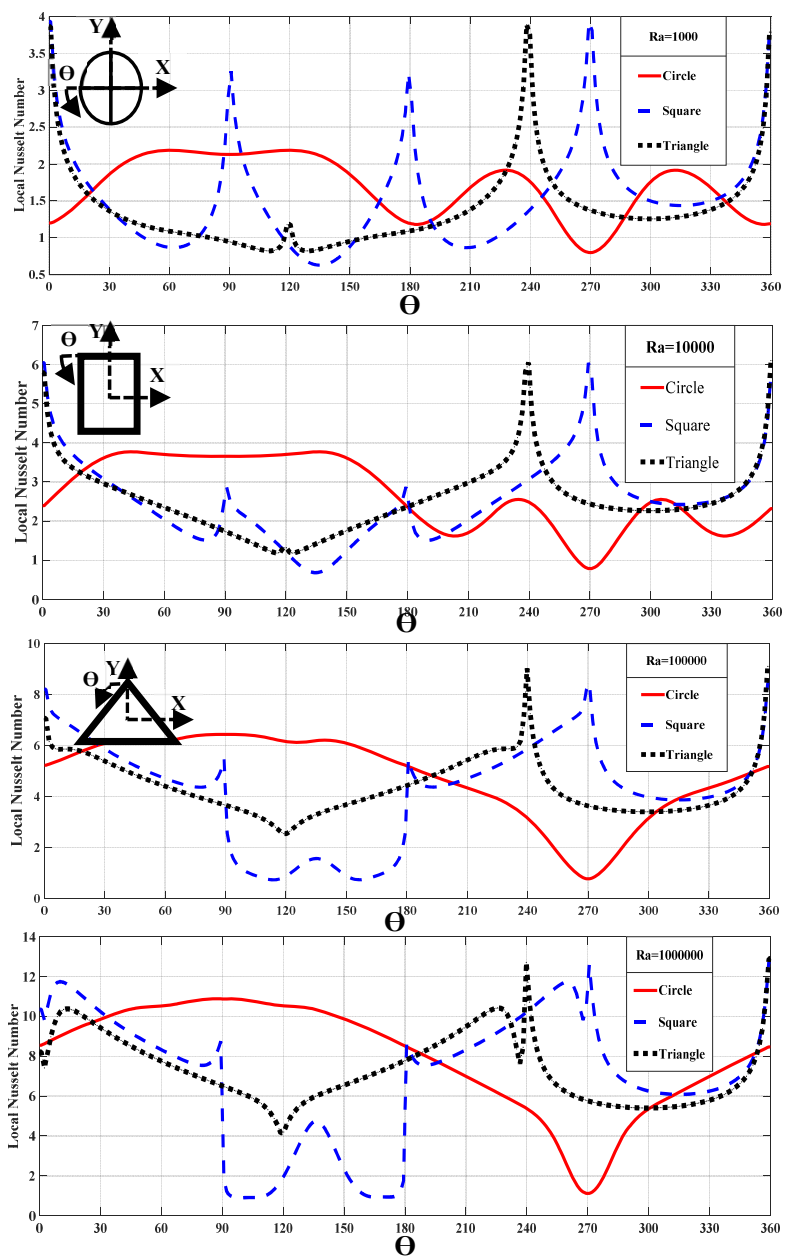

Fig. 9 Local Nusselt number around inner hot cylinders for different geometry and Rayleigh number. 
Figs. 10 (a-e) illustrates the influences of different shapes of inner cylinders and Rayleigh numbers on the contours of entropy generations that produced by heat transfer and fluid flow, total entropy generation, Bejan number and mean Nusselt Number around the hot cylinder surface.
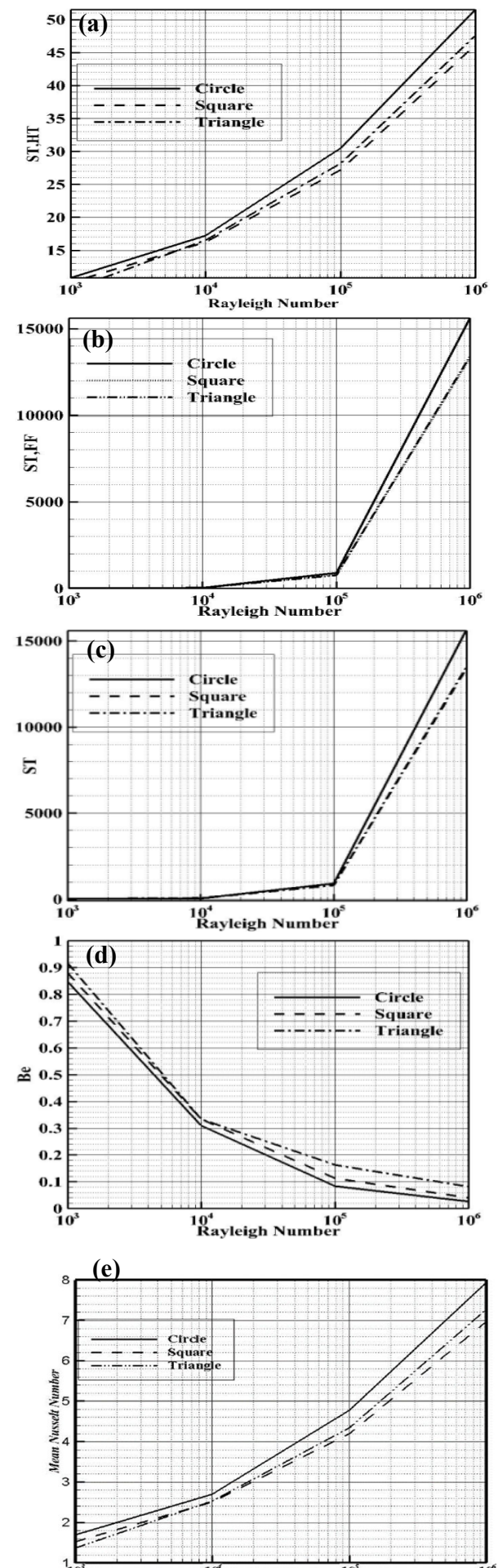

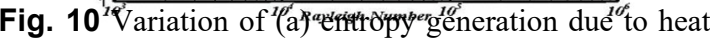
transfer, (b) entropy generation due to fluid flow, (c) total entropy generation (d) Bejan number (e) mean Nusselt number, versus Rayleigh number around different shapes of inner hot cylinders.

In all previous parameters have similar behaviors for different shapes of inner cylinders with increasing the Rayleigh Number inside a sinusoidal wall of the enclosure. It is clearly seen that the increasing of the Rayleigh number induces linear increasing of different entropy generation and mean Nusselt number due to increase the fluid movement, while values of Bejan number reduce with increasing values of Rayleigh number and vice versa. When $\mathrm{Ra}$ increases, the convective heat transfer mode dominated than the conductive mode in the cavity. Therefore, fluid friction increases and that is significantly larger compared to heat transfer irreversibilities. For this reason, Bejan number reduces with increasing Ra.

\section{CONCLUSIONS}

Entropy generation due to heat transfer and fluid flow for natural convection in a sinusoidal enclosure containing concentric cylinders with different shapes is investigated numerically. Three cases have been considered for which the three shapes of inner cylinders are circle, square, and equilateral triangle with same area. This enclosure is bounded from outside by three sinusoidal walls that are kept at a constant cold temperature while the boundaries of concentric cylinders are kept at hot temperatures. The investigation was done for Rayleigh number range, $10^{3} \leq \mathrm{Ra} \leq 10^{5}$ with Prandtl number constant $(\mathrm{Pr}=0.71)$. From the Graphical results, it is concluded that the mean Nusselt Number, entropy generations due to heat transfer and fluid flow and total entropy generation increase with increasing $\mathrm{Ra}$ for all shapes of inner cylinders while the behaviors of the local Bejan number reduces as the Ra increases. To comparison between the shapes of the hot inner cylinders, the heat transfer along the hot surface of the circle shape is higher than the other shapes as Ra increases.

\section{NOMENCLUTURE}

\section{Be Bejan Number}

$\mathrm{C}_{\mathrm{p}} \quad$ Specific heat at constant pressure $(\mathrm{KJ} / \mathrm{kg} . \mathrm{K})$

g Gravitational acceleration $\left(\mathrm{m} / \mathrm{s}^{2}\right)$

$\mathrm{k} \quad$ Thermal conductivity (W/m.K)

$\mathrm{l}_{\mathrm{c}} \quad$ Characteristic length $(\mathrm{m})$

$\mathrm{N} \quad$ Number of corrugation

$\mathrm{P} \quad$ Dimensionless pressure

$\mathrm{p} \quad$ Pressure $(\mathrm{Pa})$

Pr Prandtl number $(v / \alpha)$

$\mathrm{Ra} \quad$ Rayleigh number $\left(\mathrm{g} \beta \mathrm{L}^{3} \Delta \mathrm{T} / v \alpha\right)$

$\mathrm{R}_{\mathrm{b}} \quad$ Radius of base Circular cylinder(m)

$\mathrm{S} \quad$ Dimensionless entropy generation

$\mathrm{T}$ Temperature (K)

$\mathrm{T}_{\mathrm{o}} \quad$ Bulk temperature $\left(\mathrm{T}_{\mathrm{h}}+\mathrm{T}_{\mathrm{c}}\right) / 2(\mathrm{~K})$

$\mathrm{Nu}_{\text {Loc }}$ Local Nusselt number around hot cylinder

$\mathrm{Nu}_{\mathrm{m}} \quad$ Mean Nusselt number around hot cylinder

$\mathrm{U}$ Dimensionless velocity component in the $\mathrm{x}$-direction

$\mathrm{u} \quad$ Velocity component in $\mathrm{x}$-direction $(\mathrm{m} / \mathrm{s})$

$\mathrm{V} \quad$ Dimensionless velocity component in y-direction

v Velocity component in y-direction $(\mathrm{m} / \mathrm{s})$

$\mathrm{X}$ Dimensionless coordinate in horizontal direction

$\mathrm{x} \quad$ Cartesian coordinates in horizontal direction (m)

Y Dimensionless coordinate in the vertical direction

y Cartesian coordinate in the vertical direction (m)

\section{Greek symbols}

$\alpha \quad$ Thermal diffusivity $\left(\mathrm{m}^{2} / \mathrm{s}\right)$

$\beta \quad$ The volumetric coefficient of thermal expansion $\left(\mathrm{K}^{-1}\right)$

$\theta \quad$ Dimensionless temperature $(\mathrm{T}-\mathrm{Tc} / \Delta \mathrm{T})$

$\Psi \quad$ Dimensional stream function $\left(\mathrm{m}^{2} / \mathrm{s}\right)$

$\psi \quad$ Dimensionless stream function

$\mu \quad$ Dynamic viscosity (kg.s $/ \mathrm{m}$ )

$\varphi \quad$ Angle of rotation

$v \quad$ Kinematic viscosity $(\mu / \rho)(\mathrm{Pa} . \mathrm{s})$

$\phi \quad$ Irreversibility distribution ratio

$\Delta \mathrm{T} \quad$ Temperature difference $\left(\mathrm{T}_{\mathrm{h}}-\mathrm{T}_{\mathrm{c}}\right)$

$\rho \quad$ Density $\left(\mathrm{kg} / \mathrm{m}^{3}\right)$

$\lambda \quad$ Amplitude 


$\begin{array}{ll}\text { Subscripts } \\ \text { c } & \text { Cold } \\ \text { FF } & \text { Fluid friction } \\ \text { h } & \text { hot } \\ \text { HT } & \text { Heat transfer } \\ \text { o } & \text { Overall } \\ \text { T } & \text { Total }\end{array}$

\section{REFERENCES}

Alsabery, A. I., Ishak, M. S., Chamkha, A. J. and Hashim, I., 2018 "Entropy generation analysis and natural convection in a nanofluid-filled square cavity with a concentric solid insert and different temperature distributions," Entropy, 20(5), 336

https://doi.org/10.3390/e20050336

Al-Zamily, A. and Amin, M. R., 2015 "Natural convection and entropy generation in a nanofluid-filled semi-circular enclosure with heat flux source," Procedia Eng., 105, no. Icte, 418-424.

https://doi.org/10.1016/j.proeng.2015.05.028

Abdulkadhim A., Hamzah H. K., Abed M. A., Ali H. F., 2017, "Numerical study of entropy generation and natural convection heat transfer in trapezoidal enclosure with a thin baffle attached to inner wall using liquid nanofluid," Annales de Chimie Science des Materiaux-n ${ }^{\circ} 1$ 2, 7-28.

https://doi.org/10.3166/ACSM.41.7-28

Basak, T., Kaluri, R. S. and Balakrishnan, A. R., 2011 "Effects of thermal boundary conditions for entropy generation during natural convection," Numer. Heat Transf. Part A Appl., 59(5), 372-402. https://doi.org/10.1080/10407782.2011.549075

Erbay, L. B., Altaç, Z. and Sülüș, B., 2003 "An analysis of the entropy generation in a square enclosure," Entropy, 5, no. 5 SPEC., 496-505. https://doi.org/10.3390/e5050496

Gediz, G. M., Mobedi, and Sunden, B., 2008 "Effect of aspect ratio on entropy generation in a rectangular cavity with differentially heated vertical walls," 35, 696-703.

https://doi.org/10.1016/j.icheatmasstransfer.2008.02.002

Hussein, A. K. Kolsi Lioua, Ramesh Chand, Sivasankaran, S., Rasoul Nikbakhti, Dong Li, Borjini Mohamed Naceur, Ben Aïssia Habib, 2016 "Three-dimensional unsteady natural convection and entropy generation in an inclined cubical trapezoidal cavity with an isothermal bottom wall," Alexandria Eng. J., 55(2), 741-755.

https://doi.org/10.1016/j.aej.2016.01.004

Hussain, S. H., 2016 "Analysis of headlines and entropy generation during double-diffusive MHD natural convection within a tilted sinusoidal corrugated porous enclosure," Eng. Sci. Technol. an Int. J., 19(2), 926-945.

https://doi.org/10.1016/j.jestch.2015.12.001

Ilis, G. G., Mobedi, Sunden B.m 2008, "Effect of aspect ratio on entropy generation in a rectangular cavity with differentially heated vertical walls," International Communication Heat Mass Transfer, 35. 696-703. https://doi.org/10.1016/j.icheatmasstransfer.2008.02.002

Ismael, M. A., Armaghani, T., Chamkha, A. J., 2016 "Conjugate heat transfer and entropy generation in a cavity filled with a nanofluidsaturated porous media and heated by a triangular solid," J. Taiwan Ins. Chem. Eng. 59 138-151.

https://doi.org/10.1016/j.jtice.2015.09.012
Kaluri, R. S. and Basak, T., 2011 "Entropy generation due to natural convection in discretely heated porous square cavities," Energy, 36(8), 5065-5080

https://doi.org/10.1016/j.energy.2011.06.001

Kumar Singh, A., Roy, S., Basak, T. and Momoniat, E., 2014, "Role of entropy generation on thermal management during natural convection in a tilted square cavity with isothermal and non-isothermal hot walls," Numerical Heat Transfer, Part A, 66, 1243-1267.

https://doi.org/10.1080/10407782.2014.892402

Kumar Singh, A. Roy, S. and Basak, T., 2012 "Analysis of entropy generation due to natural convection in tilted square cavities," Ind. Eng. Chem. Res., 51(40), 13300-13318.

https://doi.org/10.1021/ie3013665

Kucuk, H., 2010 "Numerical analysis of entropy generation in concentric curved annular ducts," J. Mech. Sci. Technol., 24(9), 19271937.

https://doi.org/10.1007/s12206-010-0629-4

Mahmud, S. and Fraser, R. A., 2004 "Magnetohydrodynamic free convection and entropy generation in a square porous cavity," Int. J. Heat Mass Transfer, 47, 3245-3256.

https://doi.org/10.1016/j.ijheatmasstransfer.2004.02.005

Mahmud, S. and Sadrul Islam, A. K. M., 2003 "Laminar free convection and entropy generation inside an inclined wavy enclosure," Int. J. Therm. Sci. 42, 1003-1012.

https://doi.org/10.1016/S1290-0729(03)00076-0

Morsli, S. and Sabeur-Bendehina, A., 2014 "Numerical study on natural convection and entropy generation in squares and corrugated cavities," J. Phys. Conf. Ser., 574(1), Madrid, Spain; 08.

Nejad, S. Z., 2017 "Entropy Generation Analysis of Natural Convection in Square Enclosures with Two Isoflux Heat Sources,," Engineering Technology of Applied Science Research, 7(2), 1486-1495.

https://doi.org/10.3754/E564200

Nithyadevi, N., Divya, V. and Rajarathinam, M., 2017 "Effect of Prandt number on natural convection in a rectangular enclosure with discrete heaters," J. Apple. SCI. Eng., 20(2), 173-182.

$\underline{10.6180 / \text { jase.2017.20.2.05 }}$

Oliveski, R. D. C., Macagnan, M. H. and Copetti, J. B., 2009 "Entropy generation and natural convection in rectangular cavities," Appl. Therm. Eng., 29(8-9), 1417-1425.

https://doi.org/10.1016/j.applthermaleng.2008.07.012

Qusay Al-Amir R., Farooq Ali Alinnawi H., Hameed Hamzah K., 2017, "Effect of Wavy Wall location on the natural convection in an enclosure containing a concentric heated circular cylinder," The Iraqi Journal For Mechanical And Material Engineering, 17(2), 291-308.

https://doi.org/10.7123/IQ42001

Shavik, S., Nasim Hassan, S., Monjur Morshed, Quamerul Islam, M., M., A. K. M. M. 2013 "Natural convection and entropy generation in a square inclined cavity with differentially heated vertical walls, International," Conference on Mechanical Engineering, ICME,. https://doi.org/10.1016/j.proeng.2014.11.772

Sheremet, M. A., Oztop, H. F., Pop, I. and Abu-Hamdeh, N., 2016 "Analysis of entropy generation in natural convection of nanofluid inside a square cavity having hot solid block: Tiwari and das' model," Entropy, 18(1), 1-15.

https://doi.org/10.3390/e18010009 
Sheikholeslami, M., Gorji-Bandpy, M., Ganji, D. D., Soheil Soleimani, Seyyedi, S. M., 2012, "Natural convection of nanofluids in an enclosure between a circular and a sinusoidal cylinder in the presence of magnetic field," International Communication Heat and Mass Transfer, 39, 14351443.

https://doi.org/10.1016/j.icheatmasstransfer.2012.07.026

Sheikholeslami, M., Gorji-Bandpy, M., Pop, I., Soheil Soleimani, 2013, "Numerical study of natural convection between a circular enclosure and a sinusoidal cylinder using control volume based finite element method," International Journal of Thermal Science, 72, 147-158.

https://doi.org/10.1016/j.ijthermalsci.2013.05.004
Shi, E., He, Y., Sun, X. and Jiang, C., 2017 "Entropy Generation and Natural Convection of Air under a Magnetic Quadrupole Field in a Square Enclosure," Energy Procedia, 105, 5073-5078. https://doi.org/10.1016/j.egypro.2017.03.1027

Yehya, A. and Naji, H., 2015 "Thermal Lattice Boltzmann Simulation of Entropy Generation within a Square Enclosure for Sensible and Latent Heat Transfers," Appl. Sci., 5(4), 1904-1921.

https://doi.org/10.3390/app5041904

Zienkiewicz, O. C., Taylor, R. L., 2000, The finite element method. $5^{\text {th }}$ Edn., Oxford: Butterworth-Heinemann.

https://doi.org/10.6180/jase.2017.20.2.05 